\title{
Correction of Mandibular Prognathism in Combination with Polydiastema Using Rectangular Body Ostectomy: Literature Review and Case Report
}

\author{
Metin Sencimen', Abdullah Tugrul Coskun1, Gurkan Rasit Bayar1, Handan Altug2, \\ Hasan Ayberk Altug ${ }^{1}$, Tamer Zerener ${ }^{1}$ \\ ${ }^{1}$ Gulhane Military Medical Academy, Department of Oral Maxillofacial Surgery, Ankara, Turkey \\ ${ }^{2}$ Gulhane Military Medical Academy, Department of Orthodontics, Ankara, Turkey \\ Email: iiatcoskun@hotmail.com
}

Received 7 September 2014; revised 6 October 2014; accepted 5 November 2014

Copyright (C) 2014 by authors and Scientific Research Publishing Inc.

This work is licensed under the Creative Commons Attribution International License (CC BY).

http://creativecommons.org/licenses/by/4.0/

(c) (i) Open Access

\begin{abstract}
Objective: Mandibular prognathism is inadaptability between skull and mandible and is one phenotype of class III malocculsion. Polydiastema may be present together with class III malocclusion. Skeletal class III malocclusion with mandibular prognathism can be diagnosed by cephalometric parameters. Study Design: A 22-year-old man complaining about difficult mastication and speech was referred to Department of Oral and Maxillofacial Surgery. According to the cephalometric analysis of the patient in sagittal plane, maxilla was $3 \mathrm{~mm}$ behind and mandible was $1 \mathrm{~mm}$ ahead from the skull base. During presurgical orthodontic treatment, polydiastema was treated in maxilla and mandible. Result and Conclusions: Skeletal class III malocclusion requires an orthognathic surgical procedure including some techniques. One of these techniques is mandibular body ostectomy, which is performed often as a surgical procedure for skeletal class III malocclusion. Instead of sagittal split osteomy, the technique of madibular body ostectomy could be performed as an alternative
\end{abstract}

\section{Keywords}

Body Ostectomy, Polydiastema, Mandibular Prognathism

\section{Introduction}

The growth of the jaws and skull is associated with each other. This correlation may be changed by some eti-

How to cite this paper: Sencimen, M., Coskun, A.T., Bayar, G.R., Altug, H., Altug, H.A. and Zerener, T. (2014) Correction of Mandibular Prognathism in Combination with Polydiastema Using Rectangular Body Ostectomy: Literature Review and Case Report. Case Reports in Clinical Medicine, 3, 601-608. http://dx.doi.org/10.4236/crcm.2014.311130 
ologic factors related to congenital, developmental or acquired factors [1]. Mandibular prognathism is inadaptability between skull and mandible and is one phenotype of class III malocclusion [2]. However, according to literature, class I represents the largest group of malocclusions, followed by class II and class III [3].

Classification of skeletal class III malocclusion is done according to the position of the maxilla and the mandible, the maxillary alveolus, the mandibular alveolus and vertical development [4].

Extraorally, class III malocclusion effects the patient's profile and appearance. Concave profile is detected in these events. Also it causes difficulties in speech and mastication [5]. Intraorally, class III malocclusion is shown as a result of mandibular prognathism. Upper first molar is distal to the lower first molar in class III malocclusion. Skeletal class III malocclusion with mandibular prognathism can be diagnosed by cephalometric parameters. Characteristics with statistical significance on some cephalometric parameters are prognathic position of skeletal pogonion, negative value of E-U lip (the distance from upper lip to esthetic line) and E-L lip, (the distance from lower lip to esthetic line), negative ANB angle, increased soft tissue lower anterior facial height [6].

The treatment of class III skeletal malocclusions has been one of the most difficult problems for orthodontists. Skeletal class III malocclusions may require a combination of orthodontic and surgical treatment, which are appropriate procedure for mandibular prognathism [7]. The combined treatment for class III skeletal malocclusions has been used to achieve a functional occlusion and a normal skeletal relationship [8]. Some events, the polydiastema may be present together with class III malocclusion. Polydiastema may cause various occlusal problems, which include missing teeth, dental anomalies, dental-jaw size discrepancies, and excessive overbite and overjet. Polydiastema is diagnosed by orthodontic records and cephalometric analysis [9]. In the literature, there are some treatment protocols for diastema closure such as orthodontic, restorative and prosthodontic treatments. Polydiastema should be treated by orthodontics [10].

The technique of body ostectomy was firstly improved and recommended by Blair in 1900s [11]. Rectangular mandibular body ostectomy as a technique of ostectomy is used for skeletal class III malocclusion with edentulous gaps in dental arch [5]. Especially, the patient, who has a normal maxilla with prognathic mandible, can be treated with this surgical procedure. This procedure includes a segmental resection of a defined section of mandibular body. Before the osteotomies and resection are performed, in order to avoid damage to the nerve, it is recommended to expose and reposition for the inferior alveolar canal. As far as we know, there is not any orthognathic surgery in the treatment of skeletal class III with polydiastema.

This case report describes acombined surgical and orthodontic treatment of a case with class III malocclusion with polydiastema.

\section{Case Report}

A 22-year-old man patient with complaints about difficult mastication and speech was referred to Department of Oral and Maxillofacial Surgery. His medical history revealed that there was no systemic disease. The pretreatment lateral cephalometric and panoramic radiographs, study models and intra-extraoral photographs were taken. His extraoral examination revealed concave profile with minimal facial asymmetry. His lower lip was protruded relative to the upper lip (Figures $1(\mathrm{~A})-(\mathrm{C})$ ).

Intraoral examination revealed a class I llmolar relationship and a class III canine malocclusion with negative over jet (Figures 2(A)-(C)). Upper right deciduous canine was still present. Polydiastema were present in the anterior region of the maxilla. Owing to skeletal class III malocclusion, diastema was existing between lower canine and lower first premolar. Periodontal problem was absent in his intraoral examination.

According to the cephalometric analysis of the patient in sagittal plane, maxilla was $3 \mathrm{~mm}$ behind and mandible was $1 \mathrm{~mm}$ ahead from the skull base. In addition, the length of patient's mid-face was $2 \mathrm{~mm}$ shorter and length of lower face was $3 \mathrm{~mm}$ longer than usual. In frontal plane, there was minimum asymmetry. ANB angle was -3 degrees and SN/Go-Gn angle was 32 degrees. S-Go/N-Me ratio was 67\% (Table 1). According to the cephalometric set-up planning, if the mandible had been taken $10 \mathrm{~mm}$ behind, acceptable results of soft tissue profile would be provided. Narrowing in the maxilla was absent according to the cephalometric evaluation. Middle line deviation was $2 \mathrm{~mm}$ to the right in mandible. Upper and lower incisors inclined protrusive. In the light of these findings and result of the consultation with department of orthodontics, a skeletal class III malocclusion was diagnosed. Orthognathic surgery was planned to achieve acceptable results in aesthetic and functional aspects. 


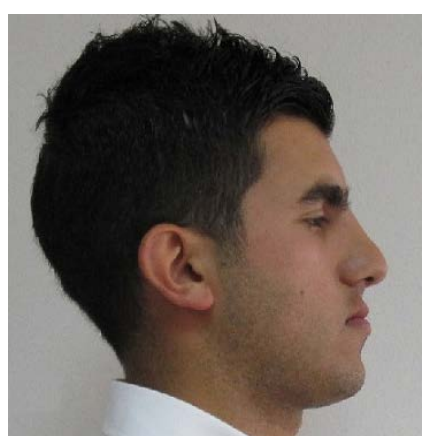

(A)

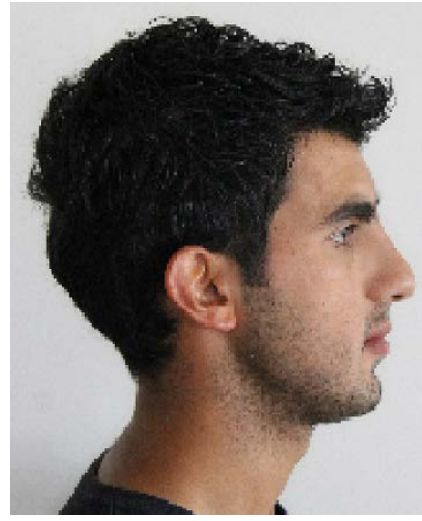

(D)

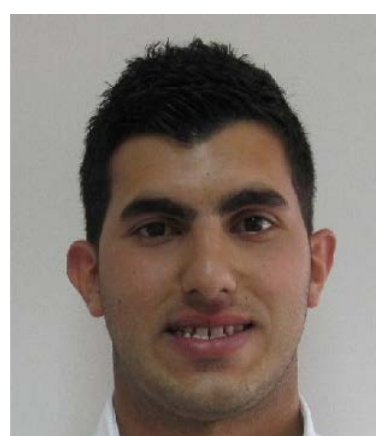

(B)

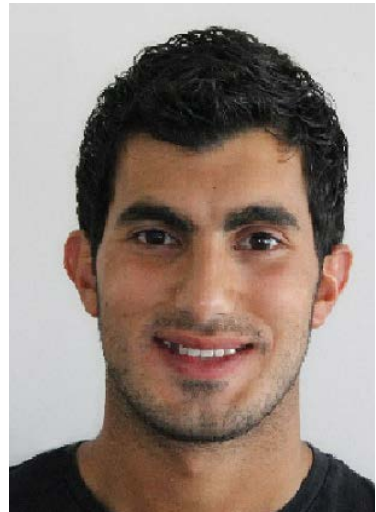

(E)

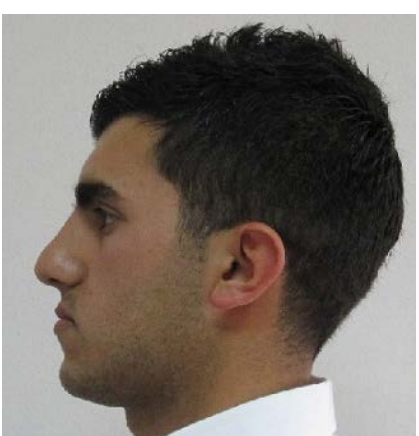

(C)

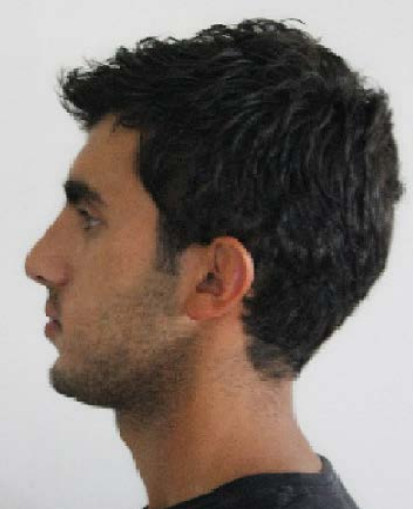

(F)

Figure 1. (A), (B) and (C) extraoral photographs of the patient before treatment; (D), (E) and (F) extraoral photographs of the patient after treatment.
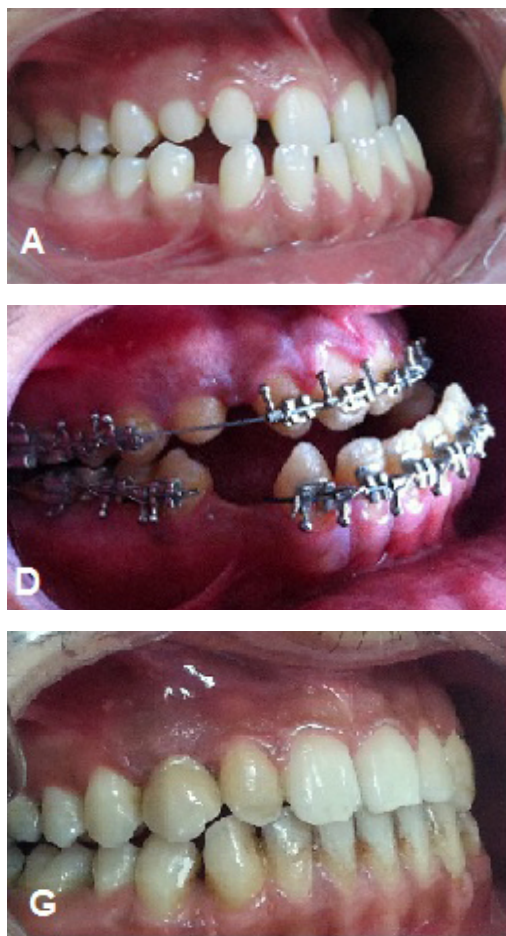
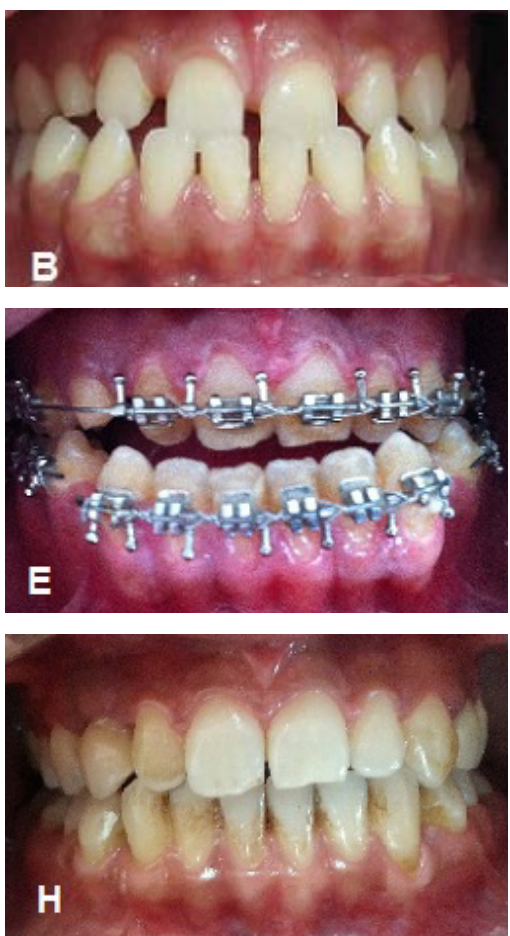
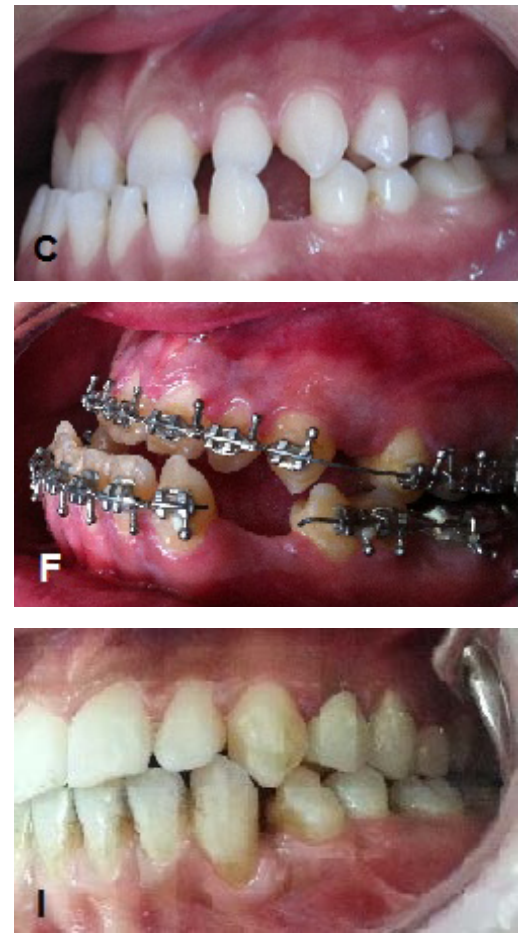

Figure 2. (A), (B) and (C) intraoral photographs of the patient before treatment; (D), (E) and (F) intraoral photographs of the patient in presurgical treatment; $(\mathrm{G}),(\mathrm{H})$ and $(\mathrm{I})$ intraoral photographs of patient after treatment. 
Table 1. Cephalometric analysis of case.

\begin{tabular}{|c|c|c|}
\hline & Preoperative & Postsurgical \\
\hline SNA & $82^{\circ}$ & $84^{\circ}$ \\
\hline SNB & $85^{\circ}$ & $82^{\circ}$ \\
\hline ANB & $-3^{\circ}$ & $2^{\circ}$ \\
\hline NV-A & -3 & -2 \\
\hline NV-Pg & -4 & -2 \\
\hline Y axle & $59^{\circ}$ & $60^{\circ}$ \\
\hline SN/ANS-PNS & $10^{\circ}$ & $9^{\circ}$ \\
\hline SN/Occ. & $14^{\circ}$ & $12^{\circ}$ \\
\hline SN/Go-Gn & $32^{\circ}$ & $35^{\circ}$ \\
\hline ANS-PNS/Go-Gn & $22^{\circ}$ & $28^{\circ}$ \\
\hline Co-A & 85 & 79 \\
\hline Co-Gn & 121 & 108 \\
\hline $\mathrm{N}-\mathrm{Me}$ & 120 & 112 \\
\hline N-ANS & 52 & 50 \\
\hline ANS-Me & 69 & 63 \\
\hline N-ANS/ANS-Me & $54 / 66$ & $50 / 62$ \\
\hline S-Go & 80 & 76 \\
\hline S-Go/N-Me & $66 \%$ & $67 \%$ \\
\hline$\underline{1 / \mathrm{SN}}$ & 115 & $121^{\circ}$ \\
\hline$\underline{1} / \mathrm{Go}-\mathrm{Gn}$ & $94^{\circ}$ & $82^{\circ}$ \\
\hline$\underline{1} / \overline{\mathrm{I}}$ & $13^{\circ}$ & $123^{\circ}$ \\
\hline$\underline{1}-\mathrm{NA}$ & $3 \mathrm{~mm}$ & $4 \mathrm{~mm}$ \\
\hline$\underline{1} / \mathrm{NA}$ & $24^{\circ}$ & $35^{\circ}$ \\
\hline$\overline{\mathrm{I}}-\mathrm{NB}$ & $8 \mathrm{~mm}$ & $4 \mathrm{~mm}$ \\
\hline$\overline{\mathrm{I}} / \mathrm{NB}$ & $30^{\circ}$ & $20^{\circ}$ \\
\hline Pg-NB & $4 \mathrm{~mm}$ & $4 \mathrm{~mm}$ \\
\hline Holdaway & $0 \mathrm{~mm}$ & $0 \mathrm{~mm}$ \\
\hline E-Line & & $-5 /-2$ \\
\hline
\end{tabular}

During presurgical orthodontic treatment, polydiastema was treated in maxilla and mandible. Deciduous upper right canine was extracted and protected its gap. In mandible, incisors were moved anteriorly to close the diastemas and provided bilaterally gaps at the posterior of the canines (Figures 2(D)-(F)). Before the surgery, a polysomnography test was performed to the patient. Apnea hypopnea index was within normal limits. For planning the osteotomy lines, a 3 dimensional solid model was provided and examined before the surgical procedure (Figure 3).

Before the surgical procedure, he was thoroughly informed about the procedure and signed a written consent. The operation was performed under general anesthesia. Bilateral N. alveolaris inferior anesthesias with vasoconstrictor were applied. Vertical and crestal incisions were made between the first premolar and canine teeth in 

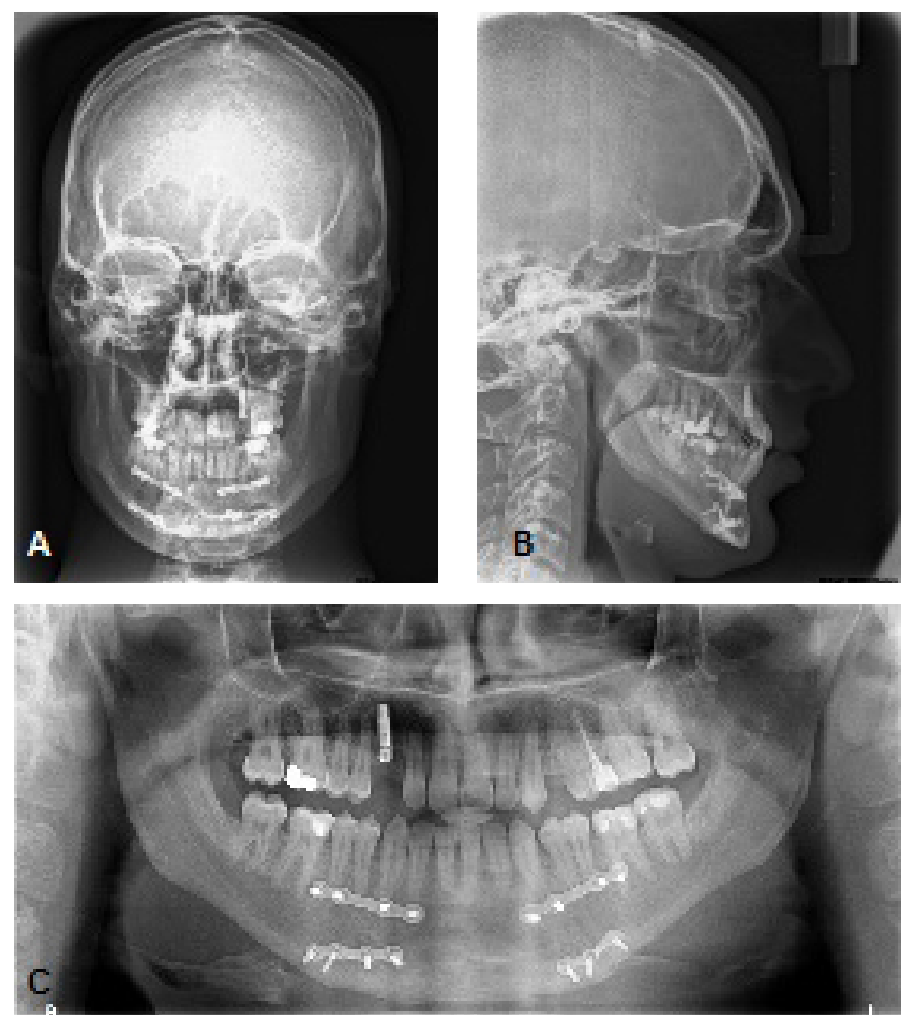

Figure 3. (A), (B) and (C) radiographic examination after treatment.

right and left side of mandible. Mucogingival flaps were raised (Figure 4(A)). The cortical bone plates were removed to expose the mental nerves (Figure 4(B) and Figure 4(C)). Ostectomy was planned as a rectangular. In each side, two parallel osteotomies were done with a burr. The neurovascular bundles were repositioned. Two bone blocks around $10 \mathrm{~mm}$ wide were removed (Figure 4(D)). Anterior mandibular segment was repositioned to the posterior. Following the intermaxillary fixation, anterior segment and basis of the mandible were secured with titanium miniplates. Bleeding control was provided, and the mucoperiosteal flap was repositioned. The flap was sutured with a $3 / 0$ silk suture material. The postoperative healing period was uneventful. His orthodontic treatment was continued for more six months without any problem. After six months, canine relationships showed class I. After the healing period, one dental implant was placed into the gap of upper right canine (Figures $5(\mathrm{~A})-(\mathrm{C})$ ). The gap of the upper right canine was eventually restored with prosthesis.

\section{Discussion}

Skeletal class III malocclusion is the one of the most complicated problems in all dentofacial abnormalities [12]. This dentofacial abnormality requires an orthognathic surgical procedure includes some techniques. One of these techniques is mandibular body ostectomy, which is performed often as a surgical procedure for skeletal class III malocclusion [13]. The technique of body ostectomy was firstly explained by Blair in 1906 [11]. The indications of mandibular body ostectomy are as follows: Edentulous mandibular prognathism, if edentulous gaps are in posterior of dental arch, if occlusion in the posterior molar region is normal, and if retrusion of the whole mandible will result in the loss of the last present teeth [14].

According to indications, our patient's examination revealed a skeletal class III malocclusion with polydiastema. During the presurgical orthodontic treatment, patient's lower incisors were moved anteriorly and edentulous gaps were obtained. In our case, according to preoperative orthodontic assessment, mandible should be taken back $10 \mathrm{~mm}$. According to the literature, if mandibular setback more than $15 \mathrm{~mm}$ required, sagittal split osteotomy should be done [15]. Thus, instead of sagittal split method, segmental osteotomy was planned.

The technique of mandibular body ostectomy provides some benefits to us for treatment of class III malocclusion. On the other hand, this technique may cause some complications. The potential complications of mandibular 

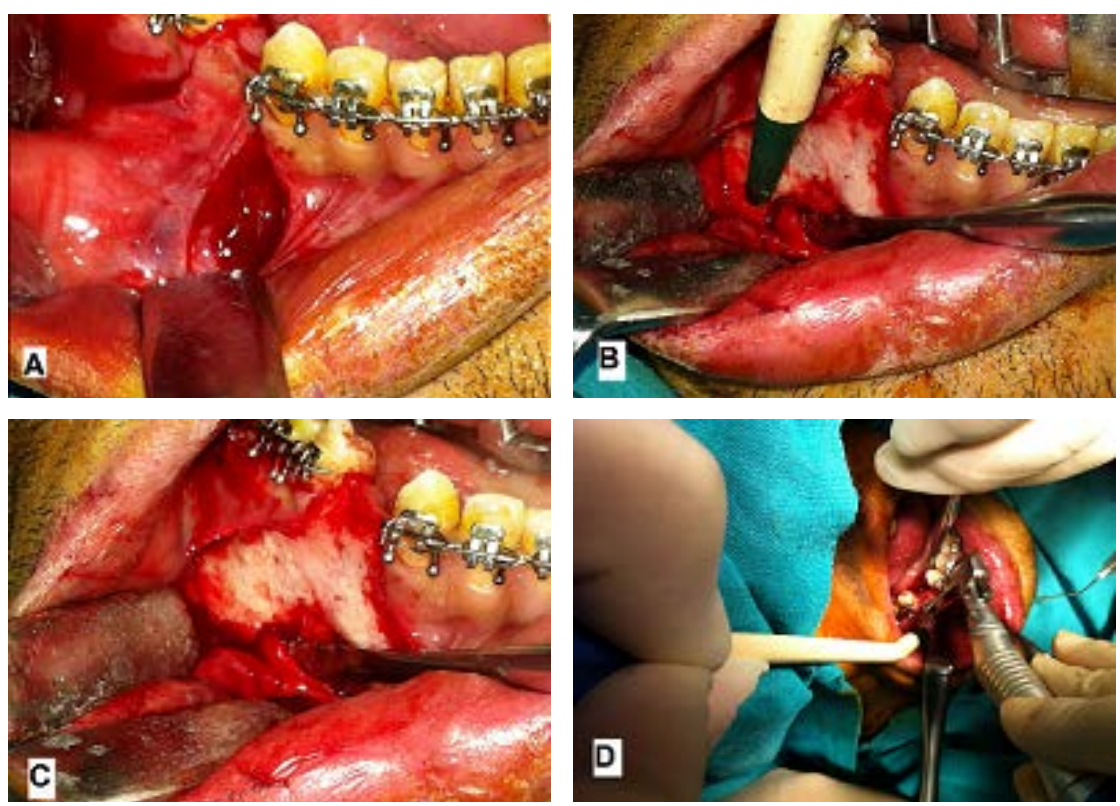

Figure 4. (A)-(D) surgical procedure.

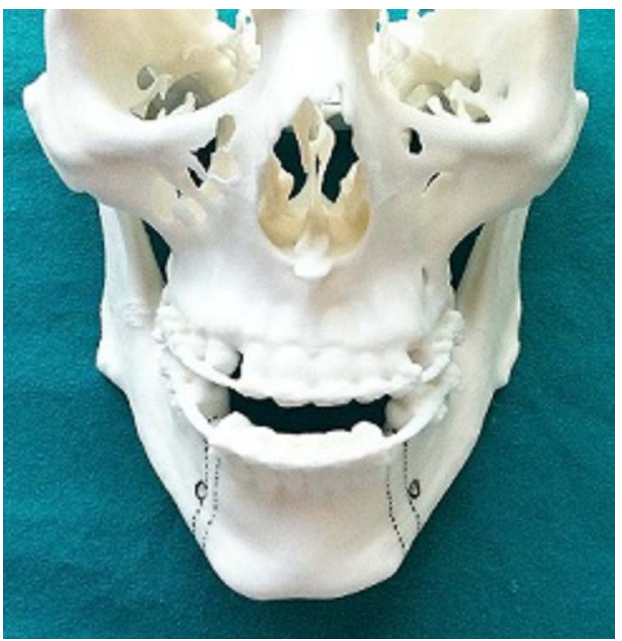

Figure 5. Patient’s 3 dimensional solid model.

body ostectomy are as follows: nerve damages, nonunion or delayed union skeletal relapse, periodontal problems of the teeth adjacent to the osteotomy sites, dental pulp devitalization and skeletal relapse [5].

There was not any complication in our case, and the postoperative healing period was uneventful. However, in the literature, the most encountered complication is skeletal relapse. Sinclair reported that the relapse of mandibular setback surgery is about $20 \%-30 \%$ and is in the anterior direction. Some different factors are related with this situation. There are mandibular growth potential and postsurgical restrictions of the space available for the tongue [16]. Occlusal stabilization is important for avoiding relapse. Therefore, miniplates or screws are used for securing. If the osteotomy sites brings together with miniplatesor screws, relapse does not appear. Especially, it was reported that the using screws for osteosynthesis is more efficient than using miniplates [17]. Although we used miniplates, there was not any relapse in our case. Additionally, Politi et al. analyzed skeletal stability after correction of skeletal class III malocclusion in relation to the type of fixation used to stabilize the mandible. This study showed that there were no differences between rigid fixation and wire osteosynthesis [18]. In addition to amount of mandibular setback, skeletal relapse in postoperative healing period is also important. According to Eggensperger, mandibular setback surgery could be done until $12 \mathrm{~mm}$ to avoid risk of skeletal re- 
lapse [19]. In accordance with the literature, anterior segment of the mandible was taken back $10 \mathrm{~mm}$ in our patient. Thereby, there was not any skeletal relapse in postoperative 6 months period.

Sometimes, facial asymmetry accompanies with skeletal class III malocclusion in high rates [1], but our patient's facial asymmetry was minimum. According to the literature, a decrease in the volume of posterior air space, and sleep apnea could be occurred after this surgical procedure [20]. In our case, narrowing of the posterior air space and sleep apnea did not exist after healing period.

Postsurgical examination was evaluated by orthopantogram, lateral cephalogram and posteroanterior cephalogram. Especially, lateral and posteroanterior cephalograms are very important for assessment of pre-post surgical procedure [21]. In presurgical period, three dimensional solid model was used for planning the surgical procedure. Also, this planning gave us extremely important visual data and maked the surgery easier. Some cases require bimaxillary surgery which is a harder surgery than a single jaw surgery [17]. Because a single jaw surgery was performed, occlusal plane alteration requireda less aggressive surgery in our case. Additionally, expectation of postoperative complications has been less than bimaxillary surgery.

According to patient's cephalometric analysis it was necessary to interfere with upper jaw surgery. On the other hand, both the patient's need for treatment of soft tissue profile and polidiastema, removal of segmental part of the lower jaw rather than upper jaw surgery thought to be more appropriate. In fact, we have obtained in the postoperative period the patient's clinical appearance of the soft tissue profile and verifies that what we say nature.

\section{Conclusion}

The mandibular body ostectomy can provide satisfying results in skeletal class III malocclusion cases. Instead of Obwegeser II osteotomy, the technique of mandibular body ostectomy could be performed as an alternative. Correct diagnosis, proper treatment plan using imaging techniques and cooperation between surgeon and orthodontist play a key role in success.

\section{References}

[1] Vasconcelos, B.C., Gonçalves, F., Andrade, A., Guillen, M. and Landim, F. (2012) Mandibular Asymmetry: Literature Review and Case Report. Brazilian Journal of Otorhinolaryngology, 78, 137. http://dx.doi.org/10.1590/S1808-86942012000400028

[2] Ho, C.T., Huang, C.S. and Lo, L.J. (2012) Improvement of Chin Profile after Mandibular Setback and Reduction Genioplasty for Correction of Prognathism and Long Chin. Aesthetic Plastic Surgery, 36, 1198-1206.

http://dx.doi.org/10.1007/s00266-012-9933-y

[3] El-Mangoury, N.H. and Mostafa, Y.A. (1990) Epidemiologic Panorama of Malocclusion. The Angle Orthodontist, 60, 207-214.

[4] Hong, S.X. and Yi, C.K. (2001) A Classification and Characterization of Skeletal Class III malocclusion on Etio-Pathogenicbasis. International Journal of Oral and Maxillofacial Surgery, 30, 264-271. http://dx.doi.org/10.1054/ijom.2001.0088

[5] Sencimen, M., Gulses, A., Sabuncuoglu, F.A., Okcu, K.M. and Olmez, H. (2012) Rectangular Body Ostectomy for the Treatment of Severe Mandibular Prognathism. Journal of Craniofacial Surgery, 23, e190-e193. http://dx.doi.org/10.1097/SCS.0b013e31824de370

[6] Chou, J.I., Fong, H.J., Kuang, S.H., Gi, L.Y., Hwang, F.Y., Lai, Y.C., Chang, R.C. and Kao, S.Y. (2005) A Retrospective Analysis of the Stability and Relapse of Soft and Hard Tissue Change after Bileteral Sagittal Split Osteotomy for Mandibular Setback of 64 Taiwanese Patients. Journal of Oral and Maxillofacial Surgery, 63, 355-361. http://dx.doi.org/10.1016/j.joms.2004.05.228

[7] Cho, H.J. (2007) Long-Term Stability of Surgical Mandibular Setback. The Angle Orthodontist, 77, 851-856. http://dx.doi.org/10.2319/052306-209.1

[8] Ravi, M.S., Shetty, N.K. and Prasad, R.B. (2012) Orthodontics-Surgical Combination Therapy for Class III Skeletal Malocclusion. Contemporary Clinical Dentistry, 3, 78-82. http://dx.doi.org/10.4103/0976-237X.94552

[9] Huang, W.J. and Creath, C.J. (1995) The Midline Diastema: A Review of Its Etiology and Treatment. Pediatric dentistry, 17, 171-179.

[10] Hwang, S.K., Ha, J.H., Jin, M.U., Kim, S.K. and Kim, Y.K. (2012) Diastema Closure Using Direct Bonding Restorations Combined with Orthodontic Treatment: A Case Report. Restorative Dentistry \& Endodontics, 37, 165-169.

http://dx.doi.org/10.5395/rde.2012.37.3.165 
[11] Blair, V.P. (1906) Report of a Case of Double Resection of the Correction of Protrusion of the Mandible. Dental Cosmos, 48, 817-820.

[12] Takahashi, H., Furuta, H., Moriyama, S., et al. (2009) Assessment of Three Bilateral Sagittal Split Osteotomy Techniques with Respect to Mandibular Biomechanical Stability by Experimental Study and Finite Element Analysis Simulation. Medical bulletin of Fukuoka University, 36, 181-192.

[13] Kawamata, A., Fujishita, M., Ariji, Y. and Ariji, E. (2000) Three Dimensional Computed Tomographic Evaluation of Morphologic Airway Changes after Mandibular Setback Osteotomy for Prognathism. Oral Surgery, Oral Medicine, Oral Pathology and Oral Radiology, 89, 278-287. http://dx.doi.org/10.1016/S1079-2104(00)70089-8

[14] Cesteleyn, L.M. and Akuamoa-Boateng, E. (1983) Surgical Correction of Mandibular Prognathism with a Functionally Stable Osteosynthesis of the Mandibular Body. British Journal of Plastic Surgery, 36, 16-21. http://dx.doi.org/10.1016/0007-1226(83)90004-8

[15] Ogasawara, T., Kitagawa, Y., Ogawa, T., Yamada, T., Nakamura, M. and Sano, K. (2002) Treatment of Severe Mandibular Prognathism in Combination with Maxillary Hypoplasia: Case Report. Journal of Craniomaxillofacial Surgery, 30, 226-229. http://dx.doi.org/10.1054/jcms.2002.0316

[16] Sinclair, P.M. (1993) The Long-Term Stability of Orthognatic Surgery. AAO Audotape, PROD, October 1993, 5-6.

[17] Yosano, A., Katakura, A., Takaki, T. and Shibara, T. (2009) Influence of Mandibular Fixation Method on Stability of the Maxillary Occlusal Plane after Occlusal Plane Alteration. Bulletin of Tokyo Dental College, 50, 71-82. http://dx.doi.org/10.2209/tdcpublication.50.71

[18] Politi, M., Costa, F., Cian, R., Polini, F. and Robiony, M. (2004) Stability of Skeletal Class III Malocclusion after Combined Maxillary and Mandibular Procedures: Rigid Internal Fixation versus Wire Osteosynthesis of the Mandible. Journal of Oral and Maxillofacial Surgery, 62, 169-181. http://dx.doi.org/10.1016/j.joms.2003.04.010

[19] Eggensperger, N., Smolka, W., Rahal, A. and Iizuka, T. (2004) Skeletal Relapse after Mandibular Advancement and Setback in Single-Jaw Surgery. Journal of Oral and Maxillofacial Surgery, 62, 1486-1496. http://dx.doi.org/10.1016/j.joms.2004.07.007

[20] Degerliyurt, K., Ueki, K., Hashiba, Y., Marukawa, K., Simsek, B., Okabe, K., Nakagawa, K. and Yamamoto, E. (2009) The Effect of Mandibular Setback or Two-Jaws Surgery on Pharyngeal Airway among Different Genders. International Journal of Oral and Maxillofacial Surgery, 38, 647-652. http://dx.doi.org/10.1016/j.ijom.2009.01.010

[21] Oltramari-Navarro, P.V., Almeida, R.R., Conti, A.C., Navarro Rde, L., Almeida, M.R. and Fernandes, L.S. (2013) Early Treatment Protocol for Skeletal Class III Malocclusion. Brazilian Dental Journal, 24, 167-173. http://dx.doi.org/10.1590/0103-6440201301588 
Scientific Research Publishing (SCIRP) is one of the largest Open Access journal publishers. It is currently publishing more than 200 open access, online, peer-reviewed journals covering a wide range of academic disciplines. SCIRP serves the worldwide academic communities and contributes to the progress and application of science with its publication.

Other selected journals from SCIRP are listed as below. Submit your manuscript to us via either submit@scirp.org or Online Submission Portal.
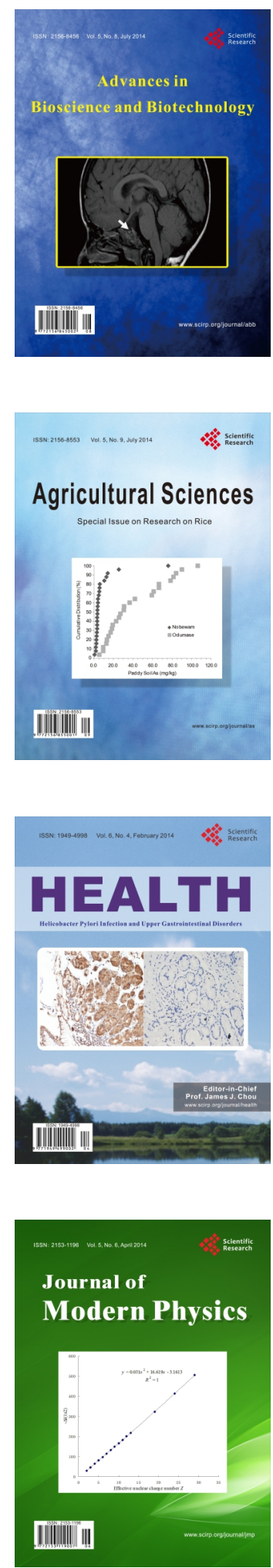
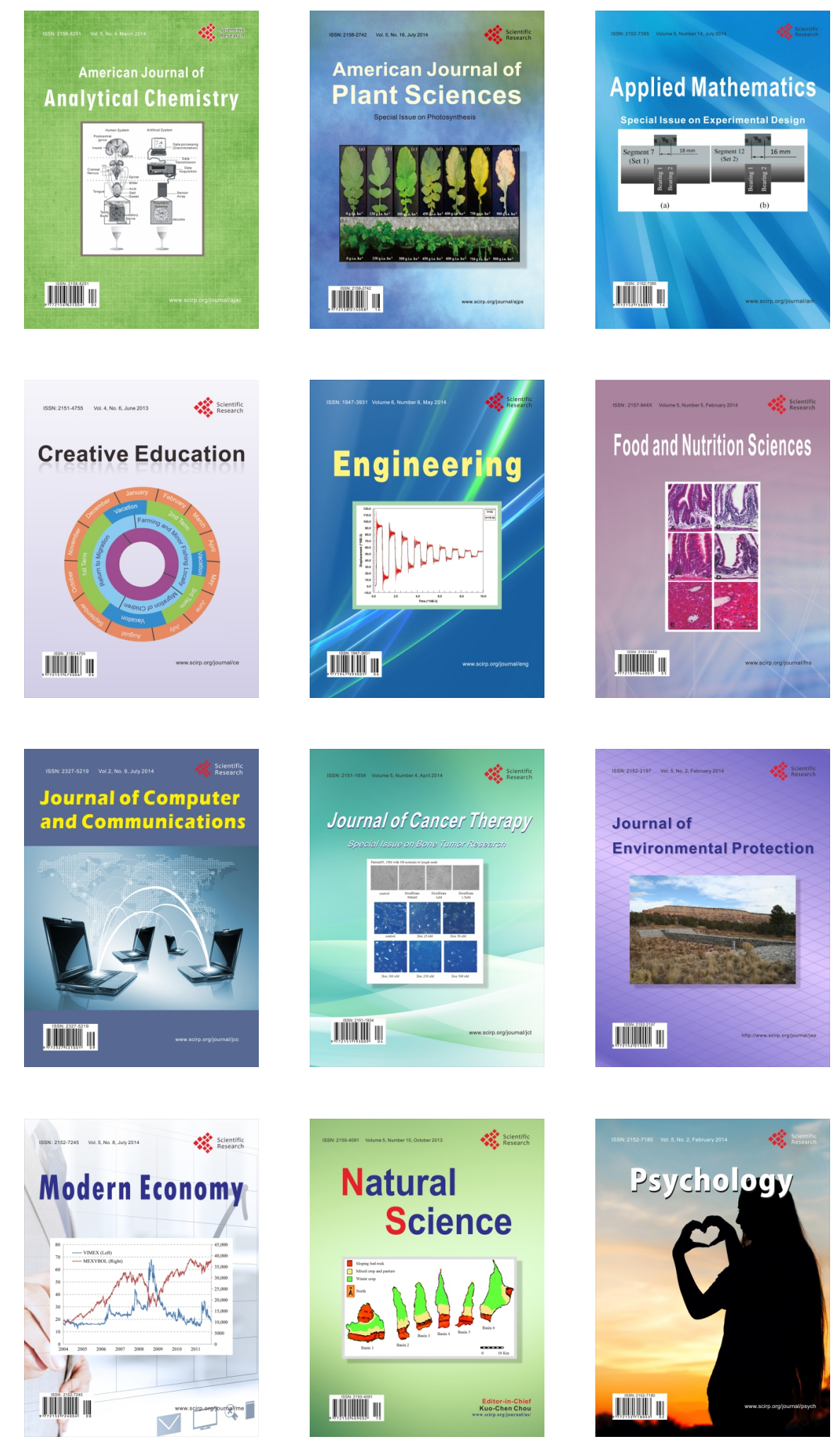